\title{
Diabetes Assessment Scales, and the Impact of Health Education on Diabetic Patient Knowledge
}

\author{
${ }^{1}$ Randah Helal, ${ }^{1}$ Noha Eladawi, ${ }^{1}$ Nadia Abd El-Hamed Montasser, ${ }^{2}$ Amr M.T. \\ Ali- Eldin
}

${ }^{1}$ Department of Public Health and Community Medicine, Faculty of Medicine, ${ }^{2}$ Department of Computer and Systems Engineering, Faculty of Engineering Mansoura University, Mansoura, Egypt.

Received: April, 2018 Accepted: June, 2018

\begin{abstract}
:
Objectives: To assess the diabetic patient condition using different diabetic scales and its relation to the blood glucose level and to assess the impact of health education message on their knowledge and to evaluate the possibility to create computational models for assessing diabetic patient condition automatically. Method: An interventional study was carried out on diabetic patients attending the diabetic clinic of Mansoura General Hospital, during the period of May to September 2015. Results: Random blood sugar showed significant positive correlation with Diabetes duration, BMI, depression and significant negative correlation with self-efficacy, empowerment, and social support, stage of change for diet and stage of change for exercise. However, diabetes activity showed significant positive correlation with different scales (Diabetes duration, BMI, social support, self-efficacy, empowerment, stage of change for diet and stage of change for exercise) except with random blood glucose and depression which showed significant negative correlation. Linear regression analysis showed that stage of change for exercise, social support, empowerment and BMI are common predictors for both random blood glucose and diabetes activity. Based on this study, two computational models could be concluded for predicting diabetes activity and random glucose level from different diabetes scales using artificial neural networks (ANNs). Improvement in the knowledge was observed after the health education setting as detected by the increase in the mean knowledge score. Conclusion: Computational models for diabetes condition assessment could be concluded where different variables under study were found related to the outcome of diabetes either management adherence or blood glucose level.
\end{abstract}

Key words: Diabetes Scales; Diabetes Control; Health Education; Statistical Analysis; Artificial Neural Networks (ANNs).

Correspondent Author: Randah helal E-mail: ranhel2000@yahoo.com

\section{Introduction}

Diabetes is undergoing unprecedented growth globally. In low and middleincome countries, the prevalence of diabetes is likely to increase by over $60 \%$ from 2012 to 2030, compared to $20 \%$ in developed countries. ${ }^{1}$ Diabetes has a great burden on health, it caused 1.5 million deaths in 2012. ${ }^{2}$ In 2013 Egypt was ranked $8^{\text {th }}$ highest country in the world in terms of diabetes rates. In 2015 the prevalence of type 2 diabetes (T2D) in Egypt was found to be around $15.6 \%$ 
of all adults aged 20 to $79 .^{3}$

The dramatic increase in the prevalence of diabetes is largely due to obesity and sedentary lifestyles. Depression appears to significantly increase the risk of developing Type 2 diabetes. ${ }^{4}$ It also increases the risk for complications of diabetes such as persistent hyperglycemia, and overall reduced quality of life with respect to psychological, physical, and social functioning. ${ }^{5}$

Diabetes is largely a preventable disease. This is where diabetic health education and public awareness becomes critically important. The disease can be prevented with early institution of effective and consistent lifestyle modifications. ${ }^{6}$ These life style modifications depend mainly on consuming healthy low calorie-diet and practicing physical exercises aiming to control hyperglycemia and to prevent diabetic complications. ${ }^{7}$ In addition, there are other attempts to manage diabetes, including social support, selfefficacy, and empowerment. ${ }^{8}$

Social support and self-efficacy influence treatment adherence of patients with chronic illness including diabetes. ${ }^{9}$ Social support is identified as a mechanism to successfully make and maintain changes. ${ }^{10}$ Self-efficacy is defined as the confidence an individual has to make decisions and carry out selfmanagement. ${ }^{11}$ Increasing self-efficacy and social support for the patients with chronic illnesses including DM can influence treatment adherence and have a positive effect on health outcomes. ${ }^{9}$ Empowerment is defined as a "process by which individuals and groups gain power, access to resources and control over their own lives. ${ }^{12}$ Empowerment is powerful in diabetic management; as patients are empowered when they have the knowledge, skills, attitudes, and selfawareness necessary to influence their own behavior and that of others to improve the quality of their lives. ${ }^{13}$
Since most of the diabetes assessment scales depend mainly on the patients' responses, it can suffer from lack of accuracy because they are rather subjective and dependent on the patient understanding and knowledge making the assessment vary from patient to another. Additionally, carrying out the different diabetes scale questionnaires can be quite cumbersome and erroneous. ${ }^{14}$ In order to avoid that, we enunciate the need for new ways to assess the influence of using the different diabetic scales on the assessment of blood glucose level and diabetes activity. Therefore, the current study was carried out to assess the diabetic patient condition using different diabetic scales and find its relation to the blood glucose level; and to assess the impact of health education message on their knowledge. Further, a new model is created to capture the influence of these scales on blood glucose level and diabetes activity using advanced computational techniques such as artificial neural networks (ANNs).

\section{Method}

This interventional study was carried out on diabetic patients of both genders attending the diabetic clinic of Mansoura General Hospital for 5 months period from May 1st, 2015 till September $30^{\text {th }}, 2015$ for obtaining their monthly drugs.

Sample size: the sample size was calculated online (dssresearch.com). A pilot study was done on 20 diabetic patients, from which the means of the scores of different questionnaires were obtained. The sample size was calculated according to these means and we took the largest sample size of 155 which was calculated according to the score of TDAQ. In that sample, the mean was $28.95 \pm 5$. By considering the worst acceptable mean as 27.95 , the 
sample size was 155 with $95 \%$ confidence level and $80 \%$ study power. We increased the sample to 300 . The patients were selected from the daily clinic list by a systematic sampling strategy, one in every 10 patients. The patients were given brief explanations of the objectives of the questionnaire. Patients were also assured of their anonymity and the confidentiality of their responses. The study was approved by the Mansoura faculty of medicine research committee.

Measures and data management: All diabetic patients of the study sample were subjected to a pre- coded interview questionnaire. The questionnaire was answered within 30 minutes and completed in the same visit. This questionnaire used to identify the following data: Socio-demographic characteristics include name, gender, age, residence, occupation, education, and family income. Social Support: Perceived social support related to diabetes from significant others, family, friends and health care professionals was measured by the Multidimensional Diabetes Questionnaire - Social Support subscale (MDQ-SS) ${ }^{15}$. The MDQ-SS consists of four items with four response options on a 1-4 rating scale. Total scores ranged from 4-16. Depression: Depression was measured by the Center for Epidemiologic Studies Depression Scale: (CES-D) ${ }^{16}$. The CES-D is a 20item with questions pertaining to frequency of depressive symptoms experienced during the previous week ${ }^{17}$. Response options range from 0 (rarely) to 3 (most or all of the time), with the total score ranging from 0-60. SelfEfficacy: Self-efficacy for diabetes selfcare was measured by the Multidimensional Diabetes Questionnaire - Self-Efficacy subscale (MDQ-SE) ${ }^{15}$. The MDQ-SE consists of 7 items with four response options ranging from "not at all confident" to "very confident." producing a possible range of 7-28. Empowerment: measured by Diabetes Empowerment Scale-Short Form (DES-SF). The DES-SF is an 8item Likert-type rating developed by researchers at the University of Michigan Diabetes Research Treatment Center (MDRTC), and have 5 Likert-type response choices: $1=$ strongly disagree, to $5=$ strongly agree. Scoring is performed by summing the total items completed and dividing by the number of items completed. Diabetes Activity: was measured by The Diabetes Activity Questionnaire (TDAQ) ${ }^{18}$. The TDAQ consists of 13 items measuring adherence to recommended diet, exercise, prescribed medication regimen, selfmonitoring of blood glucose, management of abnormal glucose levels, and daily foot inspection. Response options ranged from "never" to "always. Diet and Exercise Stage: they were measured by the Stage of Diet Scale (SODS) and the Stage of Exercise Scale (SOES) ${ }^{19}$, both consist of a five-point, ordered categorical scale and the responses ranged from 0-4. Knowledge scale ${ }^{20}$ : 12 multiple choice questions common to type 1 and type 2 diabetes, e.g. normal blood glucose levels, complications, diet, exercise, self monitoring of blood glucose, annual check-ups, support services, and sickdays; two questions for people on oral medication/insulin only; and one question (sick-days) for people with type 1 diabetes only. The intervention was in the form of health education settings about diabetes related knowledge followed by reassessment by the same knowledge scale. Investigation: All the subjects are subjected to Random blood glucose, body weight, length and BMI.

Statistical techniques: The completed questionnaires were subjected to revision and the collected data were coded, processed and analyzed through SPSS (Statistical Package for Social Sciences) 
(Standard version release 16.0). K-S was used to test the normality of different parameters. A descriptive analysis of the collected data was done in the form of frequencies and percentages. Determination of the internal consistency of different subscales was achieved by evaluating Cronbach alpha calculations. Correlation between different scales, blood glucose and BMI was examined by Spearman's correlation coefficient. The multiple linear regressions were used to assess predictors of random blood glucose and diabetes activity. $\mathrm{P} \leq 0.05$ was chosen as the level of statistical significance.

Diabetes ComputationModels using Artificial Neural Networks

Based on the statistical analysis and using regression analysis, two prediction models were concluded for both diabetes activity and glucose level. Both models recognized the association between the different diabetes scales and both diabetes activity and glucose levels. As a further step, Artificial Neural Networks (ANNs) were used to predict this association more accurately. ANNs, in addition to correlating the independent variable to a number of dependent variables, further learn from the input-output data combinations. ANNs are adopted in this work because of their suitability for fitting input output functions that are nonlinear in nature. Artificial neural networks (ANNs) are inspired by the nervous system. They use a network of nodes, to arrive at outputs from inputs. ${ }^{21}$ ANN does not require previous knowledge of the rules governing a system, making it more flexible to map between the input parameters and the output to get the best fit for a relationship model. ${ }^{22}$ In this work, a two-layer feed forward network with what are known as sigmoid hidden neurons and linear output neurons were used to fit these multi-dimensional mapping problems (mapping from different diabetes scales to one outcome). The network was trained with Leven berg-Marquardt back propagation algorithm because of its suitability for this type of problems and because it out performs other training algorithms in datasets which are not very large ${ }^{23}$. The feed forward network is composed of an input layer and an output layer where each node's influence on the nodes in the next layer is fed using a weight value. All these weights were accumulated according to the nodes states until reaching the output layer. ${ }^{24}$

\section{Results}

Three hundred diabetic patients with complete data were included in the study; their mean age was $48.9 \pm 10.7$ years. Male and female patients accounted for $37.3 \%$ and $62.7 \%$; respectively. About $50.7 \%$ of these patients were from rural areas versus $49.3 \%$ from urban areas. Nearly $37 \%$ were illiterate, $23.7 \%$ of our group had no enough income with $52.3 \%$ of them were not working. In our study, the different used scales showed good internal consistencies that were detected by reliability analysis (except the knowledge scale which showed a marginal consistency value) (MDQ-SS $=0.879$, CESD $=0.809$, MDQ-SE $=$ 0.925, DES-SF $=0.87$ and TDAQ $=$ $0.86)$ as shown in table (1). 
Table 1: Reliability of different diabetes related scales

\begin{tabular}{|c|c|c|c|}
\hline Diabetes related scales & $\begin{array}{c}\text { Cronbach's } \\
\text { Alpha }\end{array}$ & $\begin{array}{c}\text { Cronbach's } \\
\text { Alpha if item } \\
\text { deleted }\end{array}$ & $\begin{array}{l}\text { No of } \\
\text { items }\end{array}$ \\
\hline $\begin{array}{l}\text { Multi dimension Diabetes Questionnaire - Social } \\
\text { Support Subscale (MDQ-SS) }\end{array}$ & 0.879 & 0.947 & 4 \\
\hline $\begin{array}{l}\text { Center for Epidemiologic Studies Depression } \\
\text { Scale (CESD) }\end{array}$ & 0.809 & 0.843 & 20 \\
\hline $\begin{array}{l}\text { Multi dimension Diabetes Questionnaire- } \\
\text { Self-Efficacy Subscale (MDQ-SE) }\end{array}$ & 0.925 & 0.931 & 7 \\
\hline $\begin{array}{l}\text { Diabetes Empowerment Scale-Short Form (DES- } \\
\text { SF) }\end{array}$ & 0.87 & 0.892 & 8 \\
\hline Knowledge scale & 0.50 & 0.624 & 15 \\
\hline The Diabetes Activity Questionnaire (TDAQ) & 0.860 & 0.865 & 13 \\
\hline
\end{tabular}

Random blood sugar showed significant positive correlation with diabetes duration, BMI, CESD and significant negative correlation with self-efficacy, empowerment, social support stage of change for diet and stage of change for exercise. However, diabetes activity showed significant positive correlation

Table 2: Correlation between random blood glucose and The Diabetes Activity with other diabetes related scales

\begin{tabular}{lcccc}
\multicolumn{1}{c}{ Diabetes related scales } & $\begin{array}{c}\text { Random Blood } \\
\text { Sugar }\end{array}$ & P value & $\begin{array}{c}\text { Diabetes } \\
\text { Activity }\end{array}$ & P value \\
\hline Random Blood Sugar & 1 & & $-0.575^{* *}$ & $<0.001$ \\
\hline The Diabetes Activity & $-0.575^{* *}$ & $<0.001$ & 1 & \\
\hline DM duration & $.217^{* *}$ & $<0.001$ & $.161^{* *}$ & 0.005 \\
\hline BMI & $.202^{* *}$ & $<0.001$ & $.494^{* *}$ & $<0.001$ \\
\hline Social Support (MDQ-SS) & $.468^{* *}$ & $<0.001$ & $.664^{* *}$ & $<0.001$ \\
\hline Depression (CESD) & $.359^{* *}$ & $<0.001$ & $-.487^{* *}$ & $<0.001$ \\
\hline Self-Efficacy (MDQ-SE) & $-.528^{* *}$ & $<0.001$ & $.891^{* *}$ & $<0.001$ \\
\hline Empowerment (DES-SF) & $-.313^{* *}$ & $<0.001$ & $.650^{* *}$ & $<0.001$ \\
\hline Stage of Change for Diet (SODS) & $-.503^{* *}$ & $<0.001$ & $.791^{* *}$ & $<0.001$ \\
\hline Stage of Change for $\quad$ Exercise (SOES) & $-.596^{* *}$ & $<0.001$ & $.845^{* *}$ & $<0.001$ \\
\hline
\end{tabular}

Using multiple regression analysis, it is evident that stage of change for exercise, social support, empowerment and BMI are common predictors for both random blood glucose and diabetes with different scales (Diabetes duration, BMI, social support, self-efficacy, empowerment, stage of change for diet and stage of change for exercise) except with random blood glucose and CESD which showed significant negative correlation (table 2). 
Table 3: Linear regression analysis of random bloom sugar and the Diabetes Activity.

\begin{tabular}{|c|c|c|c|c|c|}
\hline \multicolumn{3}{|c|}{ Random Blood Sugar } & \multicolumn{3}{|c|}{ The Diabetes Activity } \\
\hline Predictors & $\begin{array}{c}\text { Unstandardized } \\
\text { Coefficients } \\
\text { B }\end{array}$ & $\begin{array}{c}\mathbf{P} \\
\text { value }\end{array}$ & Predictors & $\begin{array}{c}\text { Unstandardized } \\
\text { Coefficients } \\
\text { B }\end{array}$ & $\begin{array}{c}\mathbf{P} \\
\text { value }\end{array}$ \\
\hline (Constant) & 46.54 & .306 & (Constant) & 11.914 & $<0.001$ \\
\hline \multicolumn{2}{|c|}{ Stage of Change for } & $<0.001$ & \multicolumn{2}{|c|}{ Stage of Change for } & $<0.001$ \\
\hline Exercise (SOES) & -25.46 & & Exercise (SOES) & 1.165 & \\
\hline $\begin{array}{l}\text { Social Support } \\
\text { (MDQ-SS) }\end{array}$ & 5.538 & .002 & $\begin{array}{l}\text { Social Support } \\
\text { (MDQ-SS) }\end{array}$ & .232 & $<0.001$ \\
\hline Empowerment & -2.121 & .045 & Empowerment & .095 & .012 \\
\hline \multicolumn{3}{|l|}{$\overline{(\mathrm{DES}-\mathrm{SF})}$} & \multicolumn{3}{|l|}{ (DES-SF) } \\
\hline \multirow[t]{3}{*}{ BMI } & 2.570 & .001 & BMI & .064 & .025 \\
\hline & & & $\begin{array}{l}\text { Self-Efficacy } \\
\text { (MDO-SE) }\end{array}$ & .593 & $<0.001$ \\
\hline & & & $\begin{array}{l}\text { Stage of Change } \\
\text { Diet (SODS) }\end{array}$ & r.886 & $<0.001$ \\
\hline \multicolumn{6}{|l|}{ Activity } \\
\hline Model prediction & $41 \%$ & & & $85 \%$ & \\
\hline Model F & 42.2 & & & 293.2 & \\
\hline Model p & $<0.001$ & & & $<0.001$ & \\
\hline
\end{tabular}

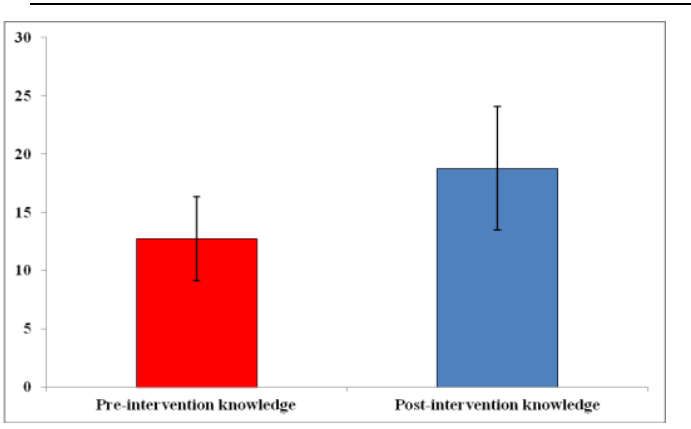

Figure (1): The mean and standard deviation of knowledge score before and after health education setting

Improvement in the knowledge was observed after the health education setting of the diabetic patients as detected by the increase of the mean score (pre-intervention score $=12.8$ \pm 3.6 and post-intervention score $=18.8 \pm$ 5.3 (figure 1). Using artificial neural networks analysis, two prediction models were generated for both diabetes activity and random glucose level respectively. We could achieve high predictability for diabetes activity (RSquare $=0.95-$ see figure $2 \mathrm{a}$ ) while considerable predictability for Random glucose levels (R-Square $=0.75-$ see figure $2 \mathrm{~b}$ ). Table 4 shows a comparison between linear regression and multilayer perception which is a sort of artificial neural networks. Results show that both models prediction error is very close.

\section{Discussion}

The growing incidence of diabetes accounts for more than $90 \%$ of all diabetes cases and the increased risk of premature illness and death and cardio vascular diseases with diabetes. In developing countries those most frequently affected are in the middle, productive years of their lives, aged between 35 and $64 . .^{25}$ The increased number of diabetes is due to increasing population growth, ageing, urbanization and increasing prevalence of obesity and physical inactivity. ${ }^{26}$ 

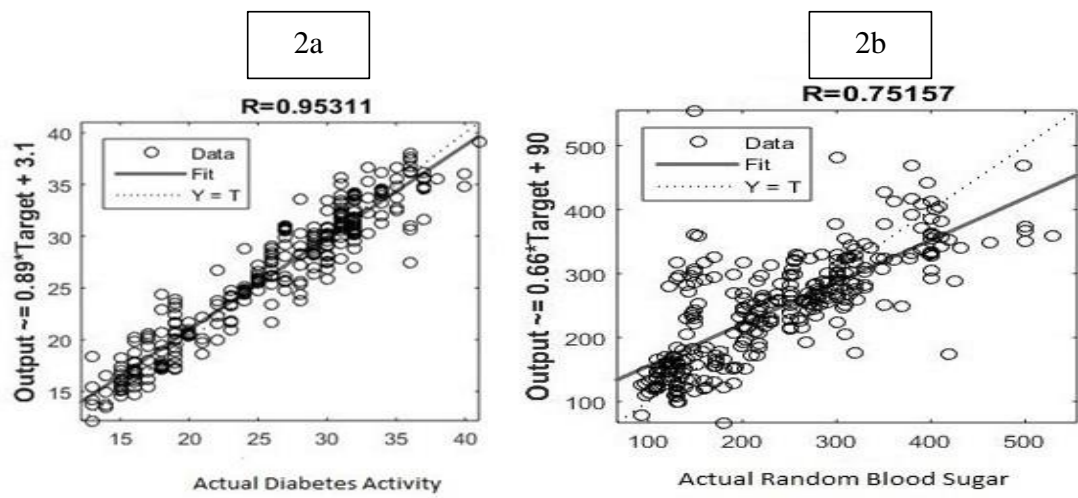

Figure (2a, b): Actual diabetes activity and random blood glucose versus predicted

Table 4: Comparison between Linear Regression and multilayer perceptron (ANN) models using mean absolute percentage error.

\begin{tabular}{lcc}
\hline \multicolumn{1}{c}{ Model } & $\begin{array}{c}\text { Random } \\
\text { Glucose } \\
\text { Level }\end{array}$ & $\begin{array}{c}\text { Disease } \\
\text { Activity }\end{array}$ \\
\hline Linear Regression & 0.27 & 0.08 \\
\hline $\begin{array}{l}\text { Mulitlayer } \\
\text { Perceptron (ANN) }\end{array}$ & 0.25 & 0.09 \\
\hline
\end{tabular}

In this study, the different used scales showed good internal consistencies' that detected by reliability analysis regarding social support scale, depression scale, self-efficacy scale and diabetes empowerment. This is similar to, Scholz et al. ${ }^{27}$ who reported high internal consistency concerning selfefficacy scale with samples from 25 nations ranged from 0.76 to 0.94 . This is in agreement with Tabachnick and Fidell $^{28}$; who also agreed that selfefficacy scale has high internal consistency. Consistently, more than 0.9 internal consistency of social support scale was reported by Tovar et al. ${ }^{29}$ and Friedlander et al. 30. Empowerment scale also has high internal consistency reliability as mentioned by Tovar et al. ${ }^{29}$ Good internal consistency concerning diabetic activity was reported by this study. In contrast, lower internal consistency was reported by Toobert et al. $^{31}$ (mean, 0.47). In this study, knowledge scale showed a marginal consistency value, however, Tovar et al. ${ }^{29}$ declared that knowledge scale internal consistency was high. Knowledge scale assesses different aspects related to diabetes and in these multidimensional scales, high reliability may not be required as reported by Tovar et al. ${ }^{29}$ who mentioned that high reliability may indicate redundancy of items.

Glycemic control is an important but complex aspect of diabetes management, with many factors necessary to maintain control. ${ }^{32}$

We declared that random blood sugar showed significant positive correlation with BMI and depression. In matching with us, Bakri ${ }^{33}$ and $\mathrm{Nisar}^{34}$ indicated that BMI is positively correlated with random blood glucose. Also, according to a recent study, $9 \%$ of patients with high random blood sugar were suffering from depressive disorders. At the same time, the association between depression and persistent hyperglycemia is reported by Petrak and Herpertz. ${ }^{35}$

In this study, random blood sugar showed a negative correlation with selfefficacy, empowerment, and social support. In agreement with us, Aalto et al. ${ }^{36}$ and Trief et al. ${ }^{10}$ reported that empowerment or self-efficacy and social support play a great role in the glycemic control and they should be researched together since such a strong correlation exists between them. 
In this study, we reported that random blood sugar showed a negative correlation with stage of change for diet and stage of change for exercise. This is matched with Thomas et al. $^{37}$ who found that increased physical activity reduces the risk of overweight or obesity, therefore improves insulin sensitivity and control random blood glucose. Also, Tovar et al. $^{29}$ reported that low-calorie diets and physical activity are promoting weight loss and controlling blood sugar.

Significant positive correlation was detected in our study between diabetes activity, and different scales (Diabetes duration, BMI, social support, selfefficacy, empowerment, stage of change for diet and stage of change for exercise). Consistently, ADA 38 indicated that diabetes activities focused on low caloric diet and physical exercise are necessary for weight reduction. Also, Anderson et al. ${ }^{7}$ reported that diabetic activities play a great role in weight management, as the reduction in excess body weight improves glycemic control and reducing random blood glucose.

In the current study, we found that diabetic activity showed a negative correlation with random blood glucose and CESD. Consistently, Daley et al. ${ }^{8}$ found that having higher depression scores is associated with lower satisfaction with taking medication, lower satisfaction with testing blood glucose. However, higher satisfaction with taking medication and testing blood glucose were strongly associated with lower blood glucose level.

We could also show that computational models for the association between diabetes scales and both random glucose levels and diabetes activity can be concluded based on this study. We used artificial neural networks to create such models where both recorded high coefficient of determinants $(\mathrm{R}$-square $=$
$0.95 \& 0.75)$ for diabetes activity and random glucose levels respectively compared to (R-square $=0.85 \& 0.42$ before using ANN). Using these models, we can further generate an autonomous tool that combines diabetes scales outputs and computes corresponding blood sugar level and diabetes activity. The use of artificial neural networks was found slightly better than linear regression for classifying random glucose but was found slightly worse for the classification of disease activity.

Life style intervention has shown effective significant changes over control in body weight and improving insulin sensitivity and that causes prevention of diabetes. ${ }^{39}$ Health education for the diabetic patient involves individualized instruction, based on the assessment of patients' psychosocial factors and selfmanagement skills and behaviors ${ }^{\mathbf{4 0}}$ and strategies to enhance and maintain the required level of physical activity and healthy diet. ${ }^{34}$ The aim of diabetic education is to enable patients to acquire knowledge and skills to improve their diabetic state, identify barriers that hinder improvement, and attain problem-solving and coping skills to achieve effective self-care behavior. ${ }^{41}$ Improvement in the knowledge was observed in our study after the health education setting of the diabetic patients. Similarly, Noris et $\mathrm{al}^{42}$ reported that diabetes health intervention has demonstrated improvements in diabetes knowledge. In a recent study examining the effects of six-month long lifestyle modification intervention, Kim et al. ${ }^{43}$ found that the intervention, composed of a curriculum covering diet, exercise, and behavior modification techniques, led to significant improvements in diabetic knowledge and glycemic control. ${ }^{29}$ Diabetes management requires 
knowledge and understanding of what to do and when and how to do it. As Bodenheimer et al. $^{44}$, declared; collaborative care and self-management education are important aspects to improve diabetic patients' knowledge. Also, knowing complications of diabetes is also helpful in reduction of morbidity and health cost. ${ }^{45}$

\section{Conclusion and Recommendation}

In this study, different variables such as psychosocial variables, empowerment, self-efficacy, and duration of diabetes were related to two outcomes of diabetes; management adherence and blood glucose level. Ongoing diabetes education and support are needed in health care systems. More interventions should be used with diabetic patients, resulting in increased support and knowledge; improvements in glycemic control and self-management behaviors. Further studies can be conducted to generate a generic tool that combines diabetes scales outputs and computes corresponding blood sugar level and diabetes activity using advanced computation techniques.

\section{References}

1. IDF Atlas 2012. Available at http://www.idf.org/sites/default/files/5E_ID FAtlasPoster_2012_EN.p df

2. WHO, 2014a. The top 10 causes of death. Fact sheet $\mathrm{N}^{\circ} 310$. Available at http://www.who.int/mediacentre/factsheets/ fs310/en/index.html

3. Hegazi R, El-Gamal M, Abdel-Hady N, Hamdy O, (2015). Epidemiology of and Risk Factors for Type 2 Diabetes in Egypt. Annals of global Health. 81(6): 814-820 4. Mezuk B, Eaton WW, Albrecht S, and Hill-Golden S. Depression and Type 2 Diabetes over the Lifespan: A metaanalysis. Diabetes Care, 2008.31:23832390.

5. Schram MT, Baan CA, Pouwer F. Depression and quality of life in patients with diabetes: a systematic review from the
European depression in diabetes (EDID) research consortium. Curr Diabetes Rev, 2009. 5(2):112-9.

6. ADA (American Diabetes Association). Standards of medical care in diabetes mellitus. Diabetes Care 2007. 30: S4-S41.

7. Anderson JW, Kendall, CW\& Jenkins DJ. Importance of weight management in type 2 diabetes: Review with meta-analysis of clinical studies. Journal of American College of Nutrition, 2003. 22(5), 331-339.

8. Daly JM, Yinghui $\mathrm{Xu}$, Barcey $\mathrm{T} \mathrm{L}$, James PA et al. An Assessment of Attitudes, Behaviors, and Outcomes of Patients with Type 2 Diabetes. JABFM, 2009 .22: 3.

9. Sayers S L, Riegel B, Pawlowski S, Coyne J C \& Samaha FF (2008). Social support and self-care of patients with heart failure. Annals of Behavioral Medicine, 2008. 35:70-79.

10.Trief PM, Ploutz-Snyder R, Britton KD, \& Weinstock RS. The relationship between marital quality and adherence to the diabetes care regimen. Annuals of Behavioral Medicine, 2004. 27(3), 148-154. University.

11.Henshaw, L. Empowerment, diabetes and the National Service Framework: A systematic review. Journal of Diabetes Nursing, 1997.10(4), 128-135.

12.Robbins SP, Chatterjee P, Canda ER. Contemporary human behavior theory. Boston: Allyn \& Bacon.1998.

13.Funnell MM and Anderson RM. Patient empowerment: a look back, a look ahead. Diabetes Educ, 2003; 29(3):454-8.

14.Donnan PT, MacDonald TM, Morris AD. Adherence to prescribed oral hypoglycaemic medication in a population of patients with Type 2 diabetes: A retrospective cohort study. Diabet Med. 2002; 19:279-84.

15. Talbot F, Nouwen A, Gingras J, Gosselin M, and Audet J. The assessment of diabetes related cognitive and social factors: The Multidimensional Diabetes Questionnaire. Journal of Behavioral Medicine, 1997.20(3), 291-312.

16.Hann D, Winter $\mathrm{K}$ and Jacobsen $\mathrm{P}$. Measurement of depressive symptoms in cancer patients. Evaluation of the Center for Epidemiological Studies Depression Scale (CES-D). Journal of Psychosomatic 
Research, 1999. 46, 437-443.

17. Radloff LS. The CES-D scale: A selfreport depression scale forresearch in the general population. Applied Psychological Measurement, 1977.1, 385-401.

18.Hernandez CA. The development and pilot testing of The Diabetes Activities Questionnaire (TDAQ): An instrument to measure adherence to the diabetes regimen. Applied Nursing Research, 1997.10(4), 202-211.

19. Cardinal B J. The stages of exercise scale and stages of exercise behavior in female adults. Journal of Sports Medicine \& Physical Fitness, 1995.35(2), 87-92.

20.Eigenmann CA, Skinner T and Colagiuri $\mathrm{R}$ : Development and validation of a diabetes knowledge questionnaire. Pract Diab Int 2011; 28 ( 4): 166-170 d www.dssresearch.com

21.Savković-Stevanović, J 'A neural network model for analysis and optimization of processes', Computers \& Chemical Engineering, 1993;17: S411-16

22.Hagan MT, Demuth HB and Beale MH. Neural Network Design, Martin Hagan Publisher, 2002.

23.Li B. and $\mathrm{Gu}$ C. 'Numerical optimization of a highly loaded compressor in semi-closed cycles using neural networks and genetic algorithms', Modeling and Analysis 2016; 6 (2), 232-250.

24.Jamali AP, Ahmadi MN and Jaafar M. 'Optimization of a novel carbon dioxide cogeneration system using artificial neural network and multi-objective genetic algorithm', Applied Thermal Engineering 2014; 64 (1-2), 293-306.

25.WHO: World health organization (2006), Global strategy on diet, physical activity and health \{Online\}. Available from:http://www.who.int/dietphysicalactivit $\mathrm{y} /$ publications/facts/diab etes.

26. Wild S, Roglic G, Green A, et al. Global prevalence of diabetes: estimates for the year 2000 and projections for 2030. Diabetes Care 2004; 27: 1047-53.

27.Scholz U, Doña BG, Sud3 S, and Schwarzer R. Is General Self- Efficacy a Universal Construct? Psychometric Findings from 25 Countries European Journal of Psychological Assessment, 2002.18; 13: 242-251.

28. Tabachnick BG, Fidel L F. Using
Multivariate Statistics. (5th ed.) Boston, MA: Allyn and Bacon.2007.

29. Tovar EG, Clark M, and Lederman R, Weller $\mathrm{S}$ et al: Relationships between Psychosocial Factors and Adherence to Diet and Exercise in Adults with Type 2 Diabetes: A Test of a Theoretical Model. The Faculty of the Graduate School of the University of Texas Medical Branch in Partial Fulfillment of the Requirements for the Degree of Doctor of Philosophy, 2007. 30.Friedlander LJ, Reid GJ, Shupak N, Cribbie R. Social support, self-esteem, and stress as predictors of adjustment to university among first-year undergraduates. Journal of College Student Development, 2007. 48, 259-274.

31.Toobert DJ, Hampson SE, Glasgow RE. The summary of diabetes self-care activities measure: results from 7 studies and a revised scale. Diabetes Care, 2000. 23(7):943-950.

32. Shiu AT, Martin CR, Thompson DR \& Wong R Y. Empowerment and metabolic control in patients with diabetes mellitus. Clinical Effectiveness in Nursing, 2005. 9, 88-91.

33.Bakari AG, Onyemelukwe G, Sani G B, Aliyu S I, Hassan S and Aliyu M T: Relationship between random blood sugar and body mass index in an African population Departments of Medicine, Chemical Pathology and Community Medicine. MSC. Ahmadu Bello University Teaching Hospital. Zaria, Nigeria.

34.Nisar N, Khan A, and Qadri3 MH, Azam S: knowledge and risk assessment of diabetes mellitus at primary care level: a preventive approach required combating the disease in a developing country. Pak J Med Sci, 2008. 24: 5.

35.Petrak F, Herpertz S. Treatment of depression in diabetes: an update. Curr Opin Psychiatry, 2009. 22(2):211-7.

36. Aalto A, Uutela A. Glycemic control, self-care behaviors, and psychosocial factors among insulin treated diabetics: A test of an extended health belief model. International Journal of Behavioral Medicine, 1997.4(3), 191-214.

37. Thomas N, Alder E, Leese GP. Barriers to physical activity in patients with diabetes. Postgrad Med J, 2004.80:287291. 
38.ADA (American Diabetes Association). Standards of medical care in diabetes, Diabetes care, 2006.29: S4 - S42.

39.ADA (American diabetes association). Standards of medical care in diabetes, Diabetes Care, 2005. 1: S4-S36.

40.Mensing C, Boucher J, Cypress M, Weinger K, Mulcahy K, Barta P, Hosey G, Kopher W, Lasichak A, Lamb B, Mangan M, Norman J, Tanja J, Yauk L, Wisdom K, Adams C: National standards for diabetes self-management education. Diabetes Care, 2006. 1:S78 - S85, 2006.

41. Mulcahy K, Maryniuk M, Peeples M, Peyrot M, Tomky D, Weaver T, and Yarborough P: Diabetes self-management education core outcomes measures: technical review. Diabetes Educ, 2003.29:768-803.
42.Norris SL, Engelgau MM, Narayan KM. Effectiveness of self- management training in type 2 diabetes: a systematic review of randomized controlled trials. Diabetes Care, 2001. 24(3):561-587.

43.Kim S H, Lee S J, Kang E S, Kang S, Lee $\mathrm{H} \mathrm{J}$, et al. Effects of lifestyle modification on metabolic parameters and carotid intima- media thickness in patients with type 2 diabetes mellitus. Metabolism, 2006. 55(8), 1053-1059.

44.Bodenheimer $\mathrm{T}$, Lorig $\mathrm{K}$, Holman $\mathrm{H}$, Grumbach K. Patient self- management of chronic disease in primary care. JAMA, 2002; 288:2469 -75.

45. Welch G, Shayne R. Interactive behavioral technologies and diabetes selfmanagement support: recent research findings from clinical trials. Curr Diab Rep 2006 Apr; 6(2):130-136. 